\title{
The Mechanism And Effects of National Smart City Pilots In China On Environmental Pollution: Empirical Evidence Based On A DID Model
}

\section{Guoxiang Xu}

Shanghai University of Finance and Economics

Zhijiu Yang ( $\square$ live_large@163.com )

SUFE: Shanghai University of Finance and Economics https://orcid.org/0000-0002-8970-8050

\section{Research Article}

Keywords: Environmental pollution, the NSC pilots, 23 Dynamic DID, Mediating effect model

Posted Date: July 23rd, 2021

DOI: https://doi.org/10.21203/rs.3.rs-618144/v1

License: (c) (i) This work is licensed under a Creative Commons Attribution 4.0 International License.

Read Full License

Version of Record: A version of this preprint was published at Environmental Science and Pollution Research on January 31st, 2022. See the published version at https://doi.org/10.1007/s11356-02118003-2. 


\title{
The mechanism and effects of national smart city pilots in China on environmental pollution: Empirical evidence based on a DID model
}

\author{
Guoxiang Xu ${ }^{1,2} \cdot$ Zhijiu Yang ${ }^{1, \bowtie}$
}

Received: date / Accepted: date

1 Abstract The policy of the national smart city (NSC) pilots, 17 a new type of urbanization for future development, has been 18 implemented in China in batches. This paper investigates 19 the mechanism and effects of the NSC pilots on the envi- 20 ronment. Using the prefecture-level panel data during 2004- 21 2018 period, our dynamic difference-in-differences (DID) estimation shows that the NSC pilots causally mitigate air ${ }^{22}$ (water) pollution by $21.5 \%(23.3 \%)$. The mediating effect model indicates that the allocation efficiency and technological innovation play a partial mediating role in the impacting mechanism. After introducing the two mediating channels into the dynamic DID model, the reduction effect for air ${ }_{25}$ (water) pollution drops to $15.5 \%(17.3 \%)$. Comparatively, improving allocation efficiency instead of technological in- ${ }_{27}$ novation takes the major mediating role in reducing air pol- ${ }_{28}$ lution, while water pollution the opposite. The result of city ${ }_{29}$

Z Zhijiu Yang

E-mail: live_large@163.com

1 School of Statistics and Management, Shanghai University of Finance and Economics, Shanghai, China

2 Research Center for Applied Statistics, Shanghai University of Fi- ${ }^{35}$ nance and Economics, Shanghai, China heterogeneity shows that cities with high human capital and fiscal support contribute to the reduction of environmental pollution. This study also provides some related policy suggestions by analyzing the initial mechanism and city heterogeneity of the NSC pilots.

Keywords Environmental pollution - the NSC pilots · Dynamic DID $\cdot$ Mediating effect model

\section{Introduction}

Since the accession to the WTO, China has experienced unprecedented economic growth with an average annual growth rate of about 10\% (Wang et al. 2021). However, this extensive economic growth mode has brought many environmental problems, such as air pollution, water deterioration, fixed waste, massive carbon dioxide emissions (Chang 2015; Tang et al. 2016; Gong et al. 2021). Increasing scholars have paid attention to the field of environment and energy, including how to lower carbon emissions (Wang et al. 2016), reduce environmental pollution (Lu and Feng 2014; Wang and Huang 2015), and conserve energy (Lin and Yang 2013; Zhang et al. 2020) . For abating "urban disease", the government of 37 China implemented the national smart city (NSC) pilots plan 
in 2012, aiming to build an environment-friendly and resources saving society (Yang 2018).

The concept of "smart city" was first originated in the 90s and developed in many Western countries (Komninos 2009; Caragliu et al. 2013). Smart city, to be specific, changes the government service mode, urban operation mode, and residents' lifestyle by using technologies and management styles to integrate the governance (Hollands 2008). During the economic transition, China has urgent demands to conserve energy and mitigate environmental pollution for sustainable development. As a result, China conducted the smart city construction plan in some pilot cities, trying to improve the efficiency of urban operation through the Internet, cloud computing, big data, and other new generation of information technology (Gu and Liu 2012; Zhao 2013). Hence, it is critical to identify the mechanism and quantify the impacts of smart city construction on the environment in China.

There are lots of factors that influence environmental 91 pollution, both positive and negative. Considering these fac- 92 tors helps us interpret the mechanism and quantify the ef- 93 fects of the NSC pilots on the environment. Existing stud- 94 ies have investigated several causal factors from different ${ }_{95}$ perspectives that have environmental impacts, like indus- 96 trial structure updating (Sun and Zhou, 2016; Liu and Lin 97 2019), industrial agglomeration (Lu and Feng 2014; Zhang 98 et al. 2019), urbanization (Wang and Wang 2016; Cui and 99 Shi 2012; Li et al. 2012), technical process and innovation ${ }_{100}$ (Bosetti et al. 2011; Li and Zhao 2011; Xu et al. 2019b;101 Shahbaz et al. 2020), environmental regulation (Levinson ${ }_{102}$ and Taylor 2008; Zhao et al. 2020; Song et al. 2020) , inter-103 national trade (Deng and Song 2008; Levinson 2009), etc.

Generally, technological innovation, industrial updating, in-104 dustrial agglomeration and strict environmental regulation ${ }_{105}$ have positive impacts on alleviating environmental pollu-106 tion, while economic growth, urbanization having time-varying effects (Gray and Shadbegian 2003; Liu et al. 2017; Zheng and Kahn 2017; Wang et al. 2021).The literature provides significant perspectives for evaluating environmental pollution, which can assist measuring the environmental effects. The NSC pilots are closely associated with the new-type urbanization in China, both integrating advanced concepts such as intensive, low-carbon, ecological into urbanization. Some researchers investigated the mechanism of new-type urbanization and analyzed the direct and indirect effects on energy consumption as well as carbon emissions (Liu et al. 2017; Wang et al. 2019). The result indicated that energysaving technologies may have a rebound effect while environmental technologies can reduce carbon emissions. Yang (2018) used the DID method to evaluate the impacts of the NSC pilots on economic efficiency, and found that the NSC pilots led to improving efficiency by $1 \%$, compared to the non-pliot cities. Simiarly, Liu and Li (2019) showed that the smart city construction policy significantly improved the efficiency of urban industrial ecological efficiency increasing about 5\%-8\%. Shi et al. (2018) evaluated the consequences of smart city construction in China under Schumpeter's innovation theory framework, illustrating the smart city contributed to the reduction of environmental pollution. But due to the limitations of the data range, their work measured the short-term effect and ignored the different batches of the NSC pilots. Based on the previous work, this paper regards the NSC pilots as the new stage of urban development, which may mainly affect the environment through three aspects: direct effect and indirect effects, including improving allocative efficiency and accelerating technological innovation.

In summary, literature on environmental pollution focused on urbanization, industrial structure, regulation (Ouyang et al. 2008; Levinson and Taylor 2009; Sun and Zhou 2016; Song et al. 2020) etc. Few pieces of researches investigated 
the impacts of the NSC pilots on environmental pollution.143 There are several problems need to be examined and quan-144 tified. First, can smart city construction in China mitigate ${ }_{45}$ environmental pollution? If so, what is the mechanism, and 146 how significant are the impacts? Second, is there any dif-147 ference in effects among these pilot cities? Cause China has 148 a vast territory, smart city construction in different regions varies a lot. We may contribute to the existing literature in the following points. First, we put forward and verify the mechanism that illustrates the possible channels of the NSC150 pilots on environmental pollution. Different from other lit-151 erature focusing on concrete factors that may influence the152 environment, this paper explains some environmental conse-153 quences of the NSC pilots from a policy perspective. Based154 on the planning and requirements, we propose three chan-155 nels, including direct effect and two mediating effects, ofi56 the NSC pilots on environmental pollution. This will help157 deepen the understanding of the NSC pilots and enrich rele-158 vant literature. Second, we employ the dynamic DID modeli59 to quantify the long-term impacts of the NSC pilots on the160 environment, which could capture the net effect of the pol-161 icy. According to the official plan, each NSC pilot will have162 a 3-5 years constructing period. The empirical result could 163 reflect the time-varying effects. Specifically, we provide in-164 sight into effectiveness of the NSC pilots policy for alleviat-165 ing pollution. The results of city heterogeneity indicate that 166 cities with agglomerated economic activities, high human 167 capital and high fiscal support have better effects on reduc-168 ing environmental pollution. Hence, we recommend some169 effective suggestions, including investing more in innova-170 tion, promoting economic agglomeration, improving educa-171 tional attainment, etc.

The remainder of the paper is organized as follows: Sec-174 tion 2 generally describes the background of smart city con-175 struction in China and leads to our dynamic DID method ${ }_{176}$ correspondingly, Section 3 proposes the impacting mechanism and some causal hypotheses, Section 4 introduces the variables and our methodologies, Section 5 presents the empirical results of the NSC pilots on environmental pollution, and the last sector concludes and provides some related policy suggestions.

\section{The NSC pilots' background}

China's extensive economic development has brought many environmental problems (Xu et al. 2019a). For protecting environment, China has taken a variety of measures, including environmental regulation, carbon trading, carbon taxing (Zhao 2017; Shi et al. 2018; Chang and Han 2020; Song et al. 2020), etc. Among these measures, smart city construction was closely related to the development of China's new urbanization. Since 2010, the Chinese government has continuously launched relevant policies to guide and encourage the construction of smart cities, aiming to promote the "no disease, less disease and quick treatment" of cities.

At the end of 2012, the Ministry of Housing and UrbanRural Development in China officially issued the NSC pilots' plan. The first batch of the NSC pilots covered 90 cities, including 37 prefecture-level cities, 50 districts (counties), and three towns. Each pilot city would go through a 3-5 years period of establishment. In these NSC pilots, China development bank corporates with the local government to invest in intelligent infrastructure, including cloud computing, 5G network, high-efficiency online platform, efficient organization etc., to realize the intelligence of the city management (Yang 2018).

Then, in 2013, the government released the second batch of the NSC pilots list, which included 103 pilot cities, including 83 at the prefecture level and 20 at the county and town level, further expanding the scale of the NSC pilots (MOHURD 2013). 
In 2015, the third batch of the NSC pilots list was re-210 leased. And by this time, the number of the NSC pilots has 211 reached 290, effectively promoting the development of Chinais new urbanization.In these NSC pilots, the central govern-213 ment has developed a three-level indicators system, includ-214 ing network infrastructure, intelligent management and ser-215 vices, industrial upgrading and new industries, to evaluate 216 the construction achievements of the pilot cities $\left(\mathrm{MOHURD}_{217}\right.$ 2012). Thus, local governments have pressure and incentives 218 to complete the evaluation, leading to difference in policies 219 and actions with non-pilot cites.

The NSC pilot's policy in China can be viewed as a221 quasi-natural experiment, where pilot cities are regarded as 222 the experimental and non-pilot cities as the control group.223 In evaluating the policy effects, DID model is universally224 used in literature, such as the impacts of bank deregulation,, 225 property tax collection, and carbon trading policy (Beck et226 al. 2010; Fan and Li 2014; Gong et al. 2021; Qi et al. 2021).227 Since the NSC pilots are carried out in batches, we adopt the 228 dynamic DID model to estimate the policy effect.

\section{Mechanism and hypotheses}

\subsection{Impacting mechanism of the NSC pilots}

This study aims to quantify the impacts of the NSC pilots ${ }_{235}$ on environmental pollution in China. Based on the require- ${ }_{236}$ ments and planning, the NSC pilots may have both direct $_{237}$ and indirect impacts on environmental pollution.

First, China is undergoing a rapid process of urbanization. The NSC pilots can improve the level of urban services and attract more residents to the cities, thus affecting the 239 environmental pollution. The impact of urbanization on en-240 vironmental pollution is not simple and linear, but has dif-241 ferent impacts at different stages and scales (Lu and Feng 242 2014; Sun and Zhou 2016). Besides, to satisfy the require-243 ments of NSC pilots planning, the municipal governments tend to introduce less-polluting industries into the local as well as drive away high-polluting industries. These highly possible measures contribute to the reduction of pollution immediately.

Second, the NSC pilots can save energy and protect the environment by improving the efficiency of resource allocation. Large-scale Internet infrastructure use, such as 5G, big data and cloud computing, enables governments, enterprises, and residents to operate and work more efficiently. For example, the rise of ride-hailing platforms has helped improve energy efficiency and protect the environment by reducing the time idling. Xu et al. (2019b) measured the carbon emission reduction by LaLaMove in 2016 with appropriate 100 million tons.

Third, the NSC pilots can help accelerate technological innovation. In these pilot cities, the governments and enterprises need to invest more capital and adopt advanced technologies to promote the construction of smart city (MOHURD 2012). In turn, it influences the environmental pollution level. besides, enterprises may have the encouragement to develop resource-saving and environment-protecting technologies. Consequently, the NSC pilots can influence environmental pollution through the technological effect .

Based on the analysis above, the impacting mechanism is shown in Figure 1. The two channels, including allocation efficiency and technological innovation, may take the mediating role in reducing environmental pollution.

\subsection{Related hypotheses}

First, compared to non-pilot cities, the NSC pilots may have unique selection and requirements for the industrial enterprises. They can affect the environmental pollution directly by attracting low-carbon and low-pollution enterprises into the districts and restricting the production of high-pollution 


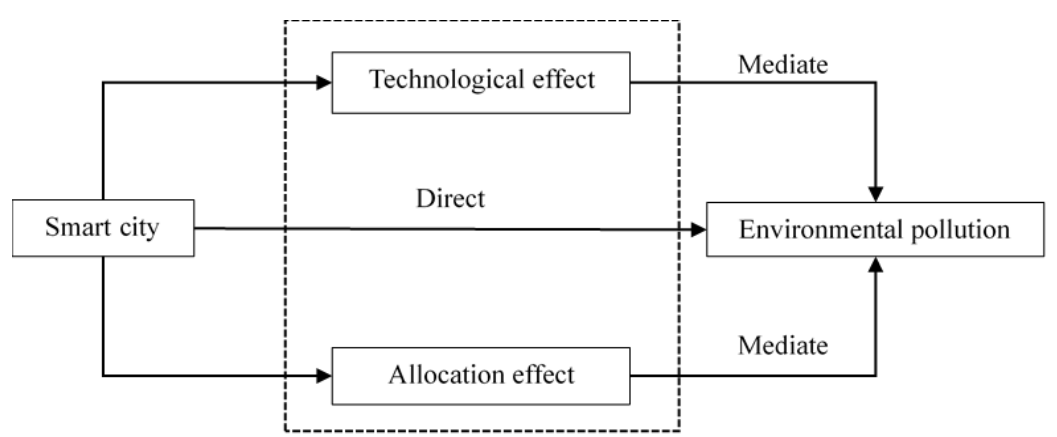

Fig. 1: Impacting mechanism of the NSC pilots

enterprises. Thus, the NSC pilots may mitigate environmen-271 tal pollution through the selection of enterprises directly.272 This paper proposes hypothesis 1 as follows.

H1: the NSC pilots can reduce environmental pollution? 74 directly

Second, with the assistance of 5G, big data, and other information technologies, smart city construction can pro- $_{276}$ mote information communication and coordination within cities, reduce transaction costs and friction costs, and $\mathrm{im}^{2}{ }^{27}$ prove resource allocation efficiency. With the aid of Internet infrastructures and online platforms, Governments can improve the efficiency of their services (Xu et al. 2012). Enterprises can monitor the market demand and planning the best route continuously with the intelligent information technology (Shi et al. 2018). As a result, smart city would reduce environmental pollution emissions comparatively. This paper proposes the following hypothesis.

H2: the NSC pilots can reduce pollution by improving ${ }_{28}$ allocation efficiency

Third, according to the policy planning and requirements of smart city construction, pilot cities have extra money and concrete guidances for investing in research and develop-288 ment, which can improve the innovation capacity of cities in ${ }_{28}$ resource-saving and environment-friendly technologies. In 990 addition, for accomplishing the smart city construction plan,291 government may impose appropriate environmental regula-292 tion, which can motivate enterprises to improve their techno-293 logical level and ability to control pollution (Shi et al. 2018). Thus, it reduces environmental pollution through technological innovation correspondingly.

H3: the NSC pilots can reduce pollution by promoting technological innovation

\section{Data and methodology}

\subsection{Data source}

The data is mainly collected from The Statistical Yearbook of Chinese Cities (2005-2019), namely data range 2004-2018. For missing data of some indicators, the average growth rate is used to make up. And all variables denoted by money are converted into the constant price of year 2004. As for the NSC pilots, this study only considers the prefecture-level cities. These non-prefecture-level cities may weaken the effects on the environment of the policy. After processing, there are 191 prefecture-level cities remained.

\subsection{Main variables}

This paper aims to examine whether the NSC pilots could contribute to the reduction of environmental pollution. Two leading indicators of pollution are adopted: industrial sulfur dioxide emissions (denoting air pollution) and wastewater emissions (denoting water pollution) (Wang and Huang 2015). Apart from the total volume, we also consider the 
pollution per capita. The indicators of pollution are mea- 328 sured in the logarithmic form.

\section{Mediating variables}

Surely, to verify the mechanism of the NSC pilots on the pollution, this study empirically investigates the mediation role of allocation efficiency and technological innovation. The origins and definations of the two variables are shown as follows:

Allocative efficiency (TFP): Scholars usually use the to- ${ }_{337}$ tal factor productivity (TFP) to represent the allocation efficiency of resources (Yang and Zhang 2020). Assuming that there are two kinds of input (labor and capital stock) and ${ }^{338}$ one output (GDP), we use the Malmquist index to measure the TFP (Liu and Li 2009). The capital given in the national statistics is a flow variable, so it needs to be converted into the stock variable: $K_{t+1}=(1-\delta) K_{t}+I_{t}$. Referenced to Guo and Guo (2019), the initial capital stock is $K_{0}=I_{0} /(g+\delta)$, depreciation rate $5 \%$, and $g$ is the geometric growth rate of fixed-asset investment growth.

Technological innovation (TI): The technological innovation is reflected in the number of patents. The more the patents are, the stronger the technological innovation is (Liu ${ }^{339}$ and $\mathrm{Li}$ 2019; Shi et al. 2018). Hence, we use the patents of each city as a proxy variable, also adopted in the logarithmic form. On the other hand, it takes some time when patents are licensed to apply. Thus, the lagging form of patents is used in the following regression.

\section{Control variables}

In line with the existing literature (Wang and Wang 2011);7 lots of factors, such as urbanization, industrial structure, etc., 348 have impacts on environmental pollution. Therefore, these variables will be included in our DID model. Thus, we include a set of prefecture-level variables to control their potential impacts on environmental pollution. The definations and descriptive statistics of control variables set are shown in Table 1.

Among the control variables, scholars usually express the proportion of non-agricultural population in the total population (Panayotou 1997; Shi et al. 2018). The prefecturelevel data standard of China is not unified, of which the integrity and quality are not satisfied. Hence, this study takes a proxy indicator of urbanization: the non-farm payrolls accounted for the proportion of the total employment (Sun and Zhou 2015).

\subsection{Dynamic DID model}

Based on the analysis, China had three batches of the national smart city pilots, respectively, in 2012, 2013, and 2015. We use a dynamic difference-in-differences (DID) specification to measure the impacts of smart city construction on the environment. And the dynamic DID model is shown as follows:

$P L T_{i t}=\alpha+\beta_{1} D_{i t}+\theta X_{i t}+\mu_{i}+\varepsilon_{i t}$

Where $P L T_{i t}$ denotes the pollution of city $i$ at time $t$, and $X_{i t}$ represents the set of control variables. $D_{i t}$ implies the DID factor, equaling one in the years after city $i$ chosen as the pilot city, otherwise zero. For example, Dongying city, located at Shandong province, China, was chosen as a NSC pilot in 2012. And the DID factor takes the value one when the year after 2012, otherwise zero. Besides, we include city-specific dummy variables to control unobserved city characteristics that influence pollution emission, and $\mu_{i}$ captures the city fixed effect.

In addition, we design the mediating effect model to verify the mechanism of the NSC pilots on pollution, which can be interpreted as a two-stage model (Hill et al. 2010). At the first stage, we should examine whether the NSC pilots have 
Table 1 Descriptive statistics of the variables

\begin{tabular}{lccccccc}
\hline Variable & Meaning & Unit & Obs & Mean & Std.Dev & Min & Max \\
\hline TFP & Total factor productivity & $/$ & 2650 & 1.059 & 0.269 & 0.253 & 11.871 \\
TI & $\begin{array}{c}\text { Number of patents, } \\
\text { in logarithmic form }\end{array}$ & $/$ & 2662 & 6.046 & 1.802 & 0.000 & 10.914 \\
& $\begin{array}{c}\text { Regional gross output } \\
\text { product per capita }\end{array}$ & $10 \mathrm{k}$ CNY/Person & 2865 & 2.235 & 1.67 & 0.008 & 16.996 \\
Den & Population density & $10 \mathrm{k}$ persons $/ \mathrm{km}^{2}$ & 2865 & 0.04 & 0.032 & 0 & 0.265 \\
Urb & Urbanzation rate & $\%$ & 2860 & 0.996 & 0.067 & 0.26 & 1 \\
Open & Foreign investment & 100 million CNY & 2711 & 15.594 & 27.815 & -3.226 & 299.213 \\
Ind & $\begin{array}{c}\text { Proportion of the secondary } \\
\text { industry in all industries }\end{array}$ & $\%$ & 2865 & 48.204 & 11.045 & 2.66 & 84.88 \\
Inf & $\quad$ Total freight & 100 million tons & 2865 & 0.768 & 1.562 & 0 & 55.42 \\
\hline
\end{tabular}

impacts on allocative efficiency and technological innova- 360 tion. That is: 361 al. 2016).

$T F P_{i t}=\alpha^{1}+\beta_{1}^{1} D_{i t}+\theta^{1} \mathbf{X}_{\mathrm{it}}+\mu_{i}+\varepsilon_{i t}$

$T I_{i t}=\alpha^{2}+\beta_{1}^{2} D_{i t}+\theta^{2} \mathbf{X}_{\mathrm{it}}+\mu_{i}+\varepsilon_{i t}$

And at the second stage, we introduce the allocative effi- ${ }^{363}$ ciency and technological innovation variables into the dynamic DID model and examine whether it is still statistically significant. The model is shown as follows:

$$
P L T_{i t}=\alpha+\beta_{1} D_{i t}+\beta_{2} T F P_{i t}+\beta_{3} T I_{i t}+\theta \mathbf{X}_{\mathrm{it}}+\mu_{i}+\varepsilon_{i t}
$$

Suppose the coefficient before the DID factor is significant in the first stage. In that case, the result indicates that the NSC pilots contribute to improving the allocation efficiency and technological innovation. At the second stage, the coefficient of DID factor is still significant, and the coefficients before the allocative efficiency and technological innovation are also significant, indicating that these two channels play a partial mediating role in the environmental pollution reduction. If the coefficient of DID factor becomes insignificant, while the two channels are significant, it indicates that allocative efficiency and technological innovation play a com-

\section{$\mathrm{y}^{364}$}

plete mediating role (see Baron and Kenny 1986; Jackson et

\section{Empirical results}

\subsection{Baseline results}

Using the dynamic DID model, Table 2 presents the effects of NSC pilots on environmental pollution. All columns consist of the prefecture-level control variables. The baseline model shows that the NSC pilots significantly reduce pollution emissions after controlling factors such as economic development, population density, urbanization level, industrial structure, etc. Compared to non-pilot cities, (1) the NSC pilots can reduce the total air pollution emission by $21.5 \%$, and reduce the wastewater emission by $23.3 \%$. The result is statistically significant at the $1 \%$ significance level. As for the pollution emission per capita, (2) the NSC pilots can reduce air pollution emission per capita by $21.9 \%$ and wastewater emission per capita by $23.8 \%$. Besides, the result also indicates that (3) economic growth, the proportion of secondary industry, and openness have significantly negative impacts on environmental pollution, while GDP per capita has the inverted U-shape effect on pollution. Like other countries, China experienced the developing pattern 


\begin{tabular}{lcccc}
\hline & \multicolumn{2}{c}{$\mathrm{SO}_{2}$ emissions } & \multicolumn{2}{c}{ Wastewater emissions } \\
\hline Variable & Total amount & Per capita & Total amount & Per capita \\
$\mathrm{D}$ & $-0.123^{* * *}$ & $-0.219^{* * *}$ & $-0.233^{* * *}$ & $-0.238^{* * *}$ \\
& $(0.046)$ & $(0.046)$ & $(0.037)$ & $(0.037)$ \\
Pgdp & $-0.493^{* * *}$ & $-0.509^{* * *}$ & $-0.254^{* * *}$ & $-0.275^{* * *}$ \\
& $(0.033)$ & $(0.032)$ & $(0.027)$ & $(0.026)$ \\
Pgdp ${ }^{2}$ & $0.025^{* * *}$ & $0.025^{* * *}$ & $0.018^{* * *}$ & 0.019 \\
& $(0.003)$ & $(0.003)$ & $(0.002)$ & $(0.002)$ \\
Growth & $0.871^{* * *}$ & $0.874^{* * *}$ & $0.457^{*}$ & $0.468^{*}$ \\
& $(0.315)$ & $(0.315)$ & $(0.255)$ & $(0.255)$ \\
Pop & $0.128^{*}$ & & 0.085 & \\
& $(0.068)$ & & $(0.55)$ & \\
Urb & -0.602 & -0.552 & 0.005 & 0.066 \\
& $(0.461)$ & $(0.460)$ & $(0.383)$ & $(0.382)$ \\
Den & $-11.83^{* *}$ & $-9.098^{*}$ & 1.378 & 2.406 \\
& $(5.055)$ & $(4.836)$ & $(4.102)$ & $(3.919)$ \\
Open & $-0.004^{* * *}$ & $-0.004^{* * *}$ & $-0.004^{* * *}$ & $-0.004^{* * *}$ \\
& $(0.003)$ & $(0.002)$ & $(0.002)$ & $(0.002)$ \\
Inf & 0.008 & 0.008 & 0.010 & 0.009 \\
& $(0.011)$ & $(0.011)$ & $(0.009)$ & $(0.009)$ \\
Obs & 2512 & 2512 & 2516 & 2516 \\
\hline
\end{tabular}

${ }^{1} \mathrm{D}$ is a binary indicator. And ***, **, * denote the significance levels at the $1 \%, 5 \%, 10 \%$ respectively. Standard errors are in parentheses. The same as below.

Table 2 The impacts of the NSC pilots on environmental pollution$$
\text { . }
$$

of "grow first, clean up later", and now China is moving to-398 wards a stage of high-quality development.

\subsection{Mechanism test}

According to the theoretical analysis above, smart city con- ${ }^{-403}$ struction may mitigate environmental pollution through two $0^{404}$ channels: improving allocation efficiency and accelerating ${ }^{405}$ technological innovation. In order to quantify the role of ${ }^{406}$ each channel, this paper uses the mediating effect model to $^{407}$ analyze the corresponding mechanism empirically (Wang et $\mathrm{e}^{408}$ al. 2021). We use the total factor productivity (TFP) to repre-409 sent allocation efficiency and the lagged patents to represent $t^{410}$ technological innovation.

The first stage regression is shown in Table 3. As can ${ }_{411}$ be seen from the table, smart city construction improves the ${ }_{112}$ total factor productivity. On average, the total factor produc-413 tivity of the NSC pilots is 0.035 higher than that of the non-414

pilot cities, which is significant at the $1 \%$ significance level.

im also statistically significant. The NSC pilots give standards and incentives for governments and enterprises to improve their technological level and ability to control pollution. The first stage regression suggests that the NSC pilots can help improve allocation efficiency and accelerate technological innovation in cities.

In order to verify that smart city construction can reduce pollution by improving allocation efficiency and promoting technological innovation, these two variables are introduced into the baseline model. The result is shown in Table 4 
Table 3 First stage regression of the mediating effect model $l_{444}$

\begin{tabular}{lcc}
\hline & TFP & TI \\
\hline $\mathrm{D}$ & $0.0035^{* * *}$ & $0.183^{* * *}$ \\
& $(0.011)$ & $(0.048)$ \\
Controls & Yes & Yes \\
Fixed & Yes & Yes \\
Obs & 2322 & 2334 \\
\hline
\end{tabular}

For air pollution, the NSC pilots help mitigate pollution mainly by improving allocation efficiency, which is statistically significant at the $1 \%$ significance level. The technological innovation variable is also negatively correlated with air pollution, but the result is not significant. After introducing the two variables into the baseline model, the effect of the NSC pilots on air pollution decreases from $21.5 \%$ to $15.5 \%$. The coefficient before the pilot variable is still significant at the $1 \%$ significance level, indicating that (1) total factor productivity and technological innovation play a partial mediating role in mitigating air pollution. Undoubtedly, improving allocation efficiency is the primary channel for 451 reducing air pollution. And we can conclude the same result $t_{452}$ for air pollution per capita.

453

As for wastewater pollution, the NSC pilots help reduce 454 pollution mainly by promoting technological innovation, whish is significant at the $1 \%$ significance level. When introducing ${ }_{456}$ the two variables into the baseline model, the direct effect of $f_{457}$ smart city pilots on water pollution decreases from $23.3 \%$ to458 $17.3 \%$. And the coefficient before the pilot variable is still 459 significant at the $1 \%$ significance level. The result also indi-460 cates that (2) total factor productivity and technological in-461 novation have a partial mediating effect on water pollution.462 And in mitigating water pollution, technological innovation ${ }_{463}$ takes a significant role.

In conclusion, the result of the mediating effect model $\mathrm{l}_{65}$ can support hypothesis 1 , hypothesis 2 , and hypothesis 3.466 The NSC pilots can mitigate environmental pollution di-467 rectly by choosing low-pollution and restricting high-pollutiøa enterprises. Besides, the NSC pilots help improve allocation efficiency and accelerate technological innovation. The two channels of smart city construction on pollution are verified. Among them, allocation efficiency has the significant effect on air pollution while technological innovation on wastewater.

\subsection{Parallel trend test}

This paper uses the parallel trend test to verify whether there are differences before and after the pilot to ensure the stability of the results. Same as the previous study (Bect et al. 2010), we consider a year-specific indicator and examine the dynamics of the relation between smart city construction and pollution. And the model is designed as follows:

$$
P L T_{i t}=\alpha+\beta_{1} D_{i t}^{-6}+\beta_{2} D_{i t}^{-5}+\cdots+\beta_{11} D_{i t}^{+4}+\theta \mathbf{X}_{\mathbf{i t}}+\mu_{i}+\varepsilon_{i t}
$$

Where $D_{i t}$ is the year-specific variable, taking a value of zero, except as follows: $D^{-j}$ equals one for cities in the $j^{t h}$ year before entering the NSC pilots' list, while $D^{+j}$ equals one for cities in the $j^{\text {th }}$ year after entering the pilot list. At the endpoints, $D_{i t}^{-6}$ equals one for all years that are six or more years before entering the list, while $D_{i t}^{+4}$ equals one for all years that are four or more years after entering the list. After de-trending and centering the estimates on the pilot year, Figure 2 plots the results and the $95 \%$ confidence intervals, which are adjusted for city-level clustering.

Figure 2 illustrates one crucial point: the impacts on environmental pollution are close to zero before the NSC pilots' policy and fall quickly after the policy. The coefficients on the dummy variables are insignificantly different from zero for all years before the pilot policy, with no trends in pollution prior to smart city construction. Next, it is clearly noted that air and wastewater pollution emissions fall immediately after the pilot policy, reaching the lowest point 


\begin{tabular}{lcccc}
\hline & \multicolumn{2}{c}{$\mathrm{SO}_{2}$ Emissions } & \multicolumn{2}{c}{ Wastewater Emissions } \\
\hline & Total amount & Per capita & Total amount & Per capita \\
$\mathrm{D}$ & $-0.155^{* * *}$ & $-0.155^{* * *}$ & $-0.173^{* * *}$ & $-0.173^{* * *}$ \\
& $(0.046)$ & $(0.046)$ & $(0.039)$ & $(0.039)$ \\
$\mathrm{T}$ & $-0.280^{* * *}$ & $-0.271^{* * *}$ & -0.063 & -0.055 \\
& $(0.087)$ & $(0.087)$ & $(0.074)$ & $(0.074)$ \\
TI & 0.022 & $-0.037^{*}$ & $-0.073^{* * *}$ & $-0.086^{* * *}$ \\
& $(0.020)$ & $(0.019)$ & $(0.017)$ & $(0.017)$ \\
Controls & Yes & Yes & Yes & Yes \\
Fixed & Yes & Yes & Yes & Yes \\
Obs & 2138 & 2138 & 2137 & 2137 \\
\hline
\end{tabular}
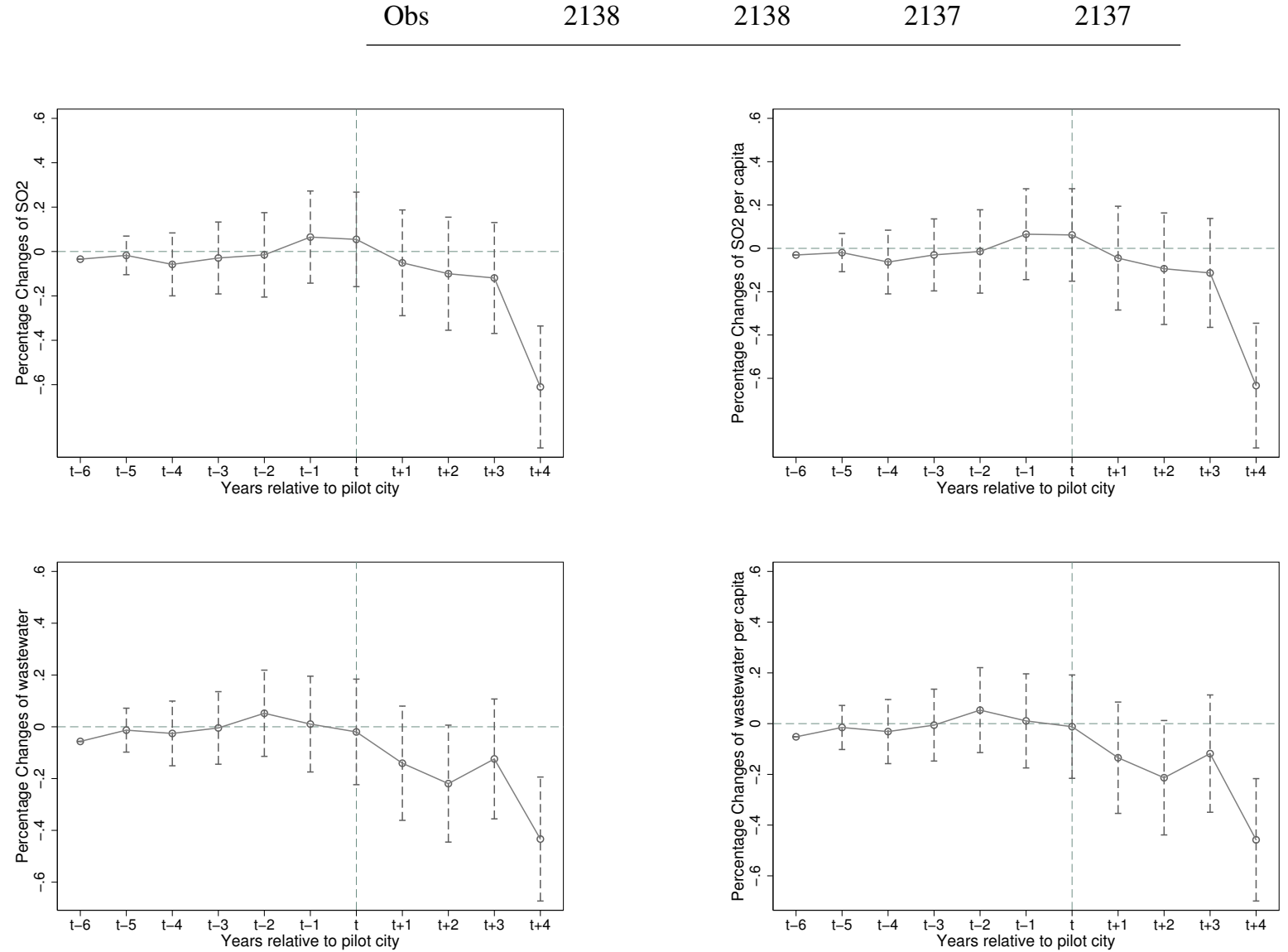

Fig. 2 The dynamic effects of pilots on environmental pollution

Table 4 Second stage regression of TFP the mediating effect model

in the fourth year. The parallel trend test shows smart city476 5.4 Placebo test

construction has a long-term effect on air and wastewater

pollution. Besides, we use the joint distribution test to verify ${ }_{477}$ The placebo test in DID can further promote the robustness whether these coefficients before the pilot policy are signifi- ${ }_{478}$ of our results (Hu and Shi 2021). In terms of dynamic DID cant. Table 5 illustrates that coefficients on the dummy vari- ${ }_{479}$ model, we randomly select 82 pilot cities (the amounts of ables are not significant from zero before pilots with small ${ }_{480}$ pilots in our sample) with smart city construction firstly and F-statistics

481 then select the pilot years randomly as the "virtual treatment". Using equation (4) as the regression form, the pro- 
Table 5 Pre-trend test

\begin{tabular}{lcccc}
\hline & $\mathrm{SO}_{2}$ & $\mathrm{SO}_{2}$ per capita & Wastewater & Wastewater per capita \\
\hline F-statistic & 0.99 & 0.89 & 0.93 & 0.84 \\
P-value & 0.4287 & 0.4989 & 0.4715 & 0.5417 \\
\hline
\end{tabular}

cess is repeated for 500 times. Intuitively, we compare the $e_{44}$ coefficients before the DID variable between the "actual treatment" and the "virtual treatment". Figure 3 shows the distri- ${ }^{495}$ bution of estimated coefficients, along with the red dashed ${ }^{496}$ line denoting the actual coefficient in Table 4 . The result il- ${ }^{497}$ lustrates the estimates from the "virtual treatment" are cen- ${ }^{498}$ tered around zero in both $\mathrm{SO}_{2}$ and wastewater emissions, ${ }^{499}$ while the actual result stays way from zero, indicating the $e^{500}$ reduction of environemtal pollution is indeed brought by the $\mathrm{e}^{501}$ NSC pilots. The finding shows that the effects of the actual ${ }^{502}$ NSC pilots on environment are robust.
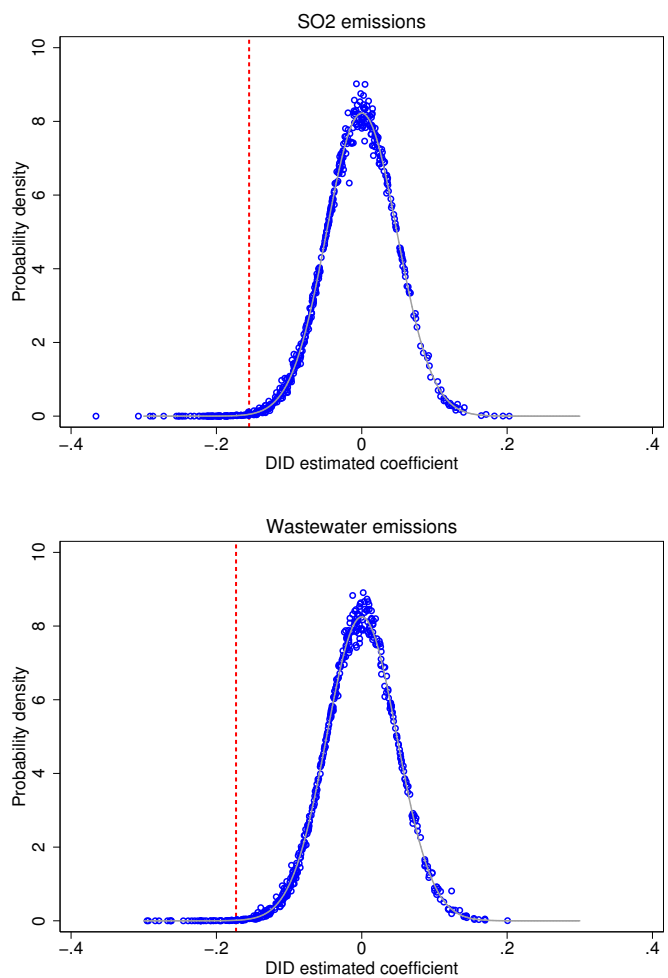

Fig. 3 Distribution of Estimated Coefficients in the Placebo test

\subsection{City heterogeneity}

Due to different economic bases, social cultures, and environmental backgrounds, the impacts of the NSC pilots may differ among these pilot cities. The fixed-effect model could not capture the difference. In order to analyze the impact of smart city construction of different cities, this paper mainly classifies cities according to their size, geographical locations and city characteristics, like human capital and fiscal support. And taking $\mathrm{SO}_{2}$ emissions as an object, we analyze the diffence of the NSC pilots on environmental pollution.

\section{City size and location}

Intuitively, large cities tend to have an agglomeration effect and higher efficiency of resource allocation (Lu and Feng 2014). For example, the popularity of online car-hailing is higher in large cities, contributing to bringing more effi-
510 511 512 513 514 516 517 518 519 ciency improvement and reducing environmental pollution.

Table 6 shows smart city construction performs well in large cities. This indicates that large cities have advantages in alleviating environmental pollution through the agglomeration of population and economic activities (Dong et al. 2020). As for location, from the west to the east, the NSC pilots are becoming less effective in reducing environmental pollution. Before the pilots, cities in the central and western regions had considerable amounts of high-polluting enterprises and serious extensive economic development. After implementing the NSC pilots, the effect of reducing environmental pollution is highly remarkable, compared to the east regions. The policy of smart city pilots helps to change the governments' development philosophy, guiding them to consider environmental pollution when pursuing economic development. 


\section{Human capital and fiscal support}

According to the relative scale of human capital and fis-552 cal support (all divided by GDP), the prefecture-level cities ${ }_{553}$ are divided into three equal parts. Similarly, we consider ${ }_{554}$ the difference between high human capital (fiscal support) $)_{555}$ and low human capital (fiscal support). Generally, cities with s56 $_{56}$ low human capital and fiscal support are relatively slow to $\mathrm{O}_{557}$ apply advanced management and high-tech applications. Thus, smart city construction has no significant effect on reduc ${ }_{-559}$ ing environmental pollution correspondingly. In cities with $_{560}$ higher levels of human capital, the planning of smart city $y_{561}$ construction is easier to carry out, resulting in the high pol $_{562}$ lution reduction effect. Table 7 indicates the result.

\section{Conclusions}

Using the prefecture-level panel data of 191 cities from 2004567 to 2018, we empirically analyze the impacts of the NSC pi-568 lots on environmental pollution in China. The results of thes 69 baseline model show that the NSC pilots can mitigate pol-570 lution emissions significantly. On average, in terms of totals71 emissions, the NSC pilots reduce environmental pollution ${ }_{572}$ by $21 \%-24 \%$, both in aggregate and per capita. The parallel 573 trend test indicates the NSC pilots have a long-term reduc-574 tion effect on environmental pollution. As smart city con-575 struction progresses, the pollution reduction effects are grad-576 ually increasing. Hence, mitigating pollution cannot happen 577 overnight, which requires long-term planning. And the pol-578 icy of the NSC pilots in China is an excellent attempt to alleviate environmental pollution systematically.

We employ the mediating effect model to verify the mechanism of the NSC pilots on environmental pollution. The first stage regression shows that the NSC pilots have significantly positive impacts on improving allocation efficiency and promoting technological innovation. On average, the NSC policy helps improve allocation efficiency by 0.035 and increases the patents by $18.3 \%$. The second stage regression indicates the partial mediating effect of improving allocation efficiency and innovation on environmental pollution. Thus, hypotheses 1,2 and 3 are supported in our analysis. As for city heterogeneity, large cities tend to have an ag-

reduce environmental pollution

With the increasing attention to the environment, society, and governance (ESG), mitigating environmental pollution becomes a hot topic. This study analyzes the impacting mechanism of the NSC pilots, which can guide the government to adopt a high-quality economic development path. The direct effect indicates that governments should practice the concept of green development, give strong supports to resource-efficient and environment-friendly enterprises. The mediating effect shows that the NSC pilots help mitigating environmental pollution through improving allocation efficiency and innovation. Therefore, governments should 


\begin{tabular}{lcccc}
\hline & High human capital & low human capital & High fiscal support & Low fiscal support \\
\hline D & $-0.297^{* * *}$ & -0.012 & $-0.212^{* * *}$ & -0.024 \\
& $(0.068)$ & $(0.122)$ & $(0.066)$ & $(0.102)$ \\
\multirow{2}{*}{ TFP } & $-0.487^{* * *}$ & -0.296 & $-0.439^{* * *}$ & -0.181 \\
& $(0.144)$ & $(0.281)$ & $(0.156)$ & $(0.158)$ \\
\multirow{2}{*}{ Patent } & 0.039 & 0.009 & 0.053 & $0.091^{* *}$ \\
& $(0.040)$ & $(0.040)$ & $(0.036)$ & $(0.042)$ \\
Fixed & Yes & Yes & Yes & Yes \\
Obs & 756 & 622 & 764 & 623 \\
\hline
\end{tabular}

promote the application of information technology, both in 604 depth and scope, and encourage enterprises to invest more in innovation and efficient organization. Moreover, the implementation of the NSC pilots requires cooperation from the public. Thus, improving the educational attainment of individuals could lead to high human capital and further pro- ${ }^{608}$ mote the smooth implementation of relevant policies. Moreover, the agglomeration of economic activities contributes to ${ }^{610}$ enhancing the environmental pollution reduction effect.

\section{Declarations}

Ethics approval and consent to participate Not applica-616 ble.

Consent for publication Not applicable.

Data availability The datasets used and analyzed during the ${ }^{619}$ current study are available from the corresponding author on ${ }^{620}$ reasonable request.

Competing interests The authors declare no competing interests.

Funding This work was financially supported by Shanghai University of Finance and Economics (CXJJ-2019-415).

Authors' contributions GX and ZY developed the conceptual framework, ZY prepared and processed the data. GX and $\mathrm{ZY}$ wrote part of the manuscript. GX supervised the final manuscript. All authors read and approved the final manuscript.

\section{References}

Baron RM, Kenny DA (1986) The moderator-mediator variable distinction in social psychological research: Conceptual, strategic, and statistical considerations. J Pers Soc Psychol 51(6):1173-1182

Beck T, Levine R, Levkov A (2010) Big bad banks? the winners and losers from bank deregulation in the united states. J Financ 65(5):1637-1667

Bosetti V, Carraro C, Duval R, Tavoni M (2011) What should we expect from innovation? a model-based assessment of the environmental and mitigation cost implications of climate-related r\&d. Energy Econ 33(6):13131320

Caragliu A, Del Bo C, Nijkamp P (2013) Smart cities in Europe. Routledge

Chang N (2015) Changing industrial structure to reduce carbon dioxide emissions: a chinese application. J Clean Prod 103:40-48

Chang N, Han C (2020) Cost-push impact of taxing carbon in china: A price transmission perspective. J Clean Prod 248:1-9

Cui L, Shi J (2012) Urbanization and its environmental effects in shanghai, china. Energy Econ 2:1-15

Deng BS, Song DY (2008) A research on the relationship of foreign trade, fdi and environment pollution: 1995- 2005. J Int Trade 4:101-108 
Dong F, Wang Y, Zheng L, Li J, Xie S (2020) Can indus-665 trial agglomeration promote pollution agglomeration? ev-666 idence from china. J Clean Prod 246:1-13

667

Fan ZY, Li X (2014) Political connection of ministers and 668 the allocation of fiscal transfer. Econ Res J 6:129-141 ${ }_{669}$

Gong C, Zhang J, Liu H (2021) Do industrial pollution ac-670 tivities in china respond to ecological fiscal transfers? ev-671 idence from payments to national key ecological function 672 zones. J Environ Plan Manag 64:1184-1203

673

Gray WB, Shadbegian RJ (2003) Plant vintage, technology,674 and environmental regulation. J Environ Econ and Manag 675 46(3):384-402

676

Gu S, Liu J (2012) Urbanization transition in china: From677 a factor-driven to an innovation-driven approach. Popul678 Res 36:3-12

Guo SF, Guo JH (2019) The establishment of 'compre- 680 hensive reform zone', industrial diversification and high-681 quality development of resource-based regions. Ind Econ 682 Res 1:87-98

683

Hill WR, Ryon MG, Smith JG, Adams SM, Boston HL,684 Stewart AJ (2010) The role of periphyton in mediating the 685 effects of pollution in a stream ecosystem. Environmental 686 Management 45(3):563-576

Hollands RG (2008) Will the real smart city please stand up?688 City 12(3):303-320

Hu K, Shi D (2021) The impact of government-enterprise 690 collusion on environmental pollution in china. Journal of $f_{691}$ Environmental Management 292:1-7

692

Jackson SA, Gopalakrishna-Remani V, Mishra R, Napier R693 (2016) Examining the impact of design for environment 694 and the mediating effect of quality management innova-695 tion on firm performance. Int J Prod Econ 173:142-152 696 Komninos N (2009) Intelligent cities: towards interactive 697 and global innovation environments. Int J Innov Reg Dev698 1(4):337-355
Levinson A (2009) Technology, international trade, and pollution from u.s. manufacturing. Am Econ Rev 99:21772192

Levinson A, Taylor MS (2008) Unmasking the pollution haven effect. Int Econ Rev 49(1):223-254

Li B, Zhao XH (2011) Economic structure, technological progress and environmental pollution: Based on the analysis of industrial data in china. J Financ Econ 37:112-122

Li Y, Li Y, Zhou Y, Shi Y, XD Z (2012) Investigation of a coupling model of coordination between urbanization and the environment. J Environ Manage 98:127-133

Lin B, Yang L (2013) The potential estimation and factor analysis of china's energy conservation on thermal power industry. Energy Policy 62:354-362

Liu BL, Li QB (2009) The dynamic analysis of china's city tfp: 1990-2006-based on the malmquist index and dea model. Nankai Econ Stud 3:139-152

Liu K, Lin B (2019) Research on influencing factors of environmental pollution in china: A spatial econometric analysis. J Clean Prod 206:356-364

Liu Y, Xiao H, Lv Y, Zhang N (2017) The effect of new-type urbanization on energy consumption in china: a spatial econometric analysis. J Clean Prod 163:299-305

Lu M, Feng H (2014) Agglomeration and emission reduction: An empirical study of the impact of urban size gap on industrial pollution intensity. J World Econ 7:86-114

MOHURD (2012) National smart city (district, town) pilot indicator system (trial). http: //www.gov . cn/gzdt/ 2012-12/10/content_2286787.htm

MOHURD (2013) The ministry of housing and urban-rural development has released a list of 103 national pilot smart cities. http://www.gov.cn/jrzg/2013-08/05/ content_2461575.htm

Ouyang T, Fu S, Zhu Z, Kuang Y, Huang N, Wu Z (2008) A new assessment method for urbanization environmental 
impact: urban environment entropy model and its appli-735 cation. Environ Monit Assess 146(1):433-439

Panayotou T (1997) Demystifying the environmental 37 kuznets curve: Turning a black box into a policy tool. En-738 viron Dev Econ 2:465-484

Qi S, Cheng S, Cui J (2021) Environmental and economic/40 effects of china's carbon market pilots: Empirical evi-741 dence based on a did model. J Clean Prod 279:1-10 742

Shahbaz M, Raghutla C, Song M, Zameer H, Jiao Z (2020) 43 Public-private partnerships investment in energy as new $\mathrm{W}_{74}$ determinant of co2 emissions: The role of technological 745 innovations in china. Energy Econ 86:1-12

Shi DQ, Ding H, Wei P, Liu JJ (2018) Can smart city con-747 struction reduce environmental pollution. China Ind Econ ${ }_{78}$ 6:117-135

Song Y, Yang T, Li Z, Zhang X, Zhang M (2020) Research ${ }_{50}$ on the direct and indirect effects of environmental regula-751 tion on environmental pollution: Empirical evidence from ${ }_{752}$ 253 prefecture-level cities in china. J Clean Prod 269:1-753 15

Sun JW, Zhou YL (2015) Urban-rural disparity, labor mi-755 gration and urbanization. Econ Rev 192:29-40

Sun YF, Zhou M (2016) Impact of urbanization and higher 757 performance industrial $\mathrm{s}$ tructure on $\mathrm{co} 2$ emissions in $\mathrm{n}_{58}$ china: independent and coupling effects. Resour Scir59 38:1846-1860

Tang W, Wu L, Qian H (2016) From pollution-heaven ${ }_{61}$ to green-growth: Impact of carbon-market relocation of $f_{62}$ energy-intensive-sectors. Econ Res J 51:58-70

Wang H, Wang Q (2011) The pollution emission and urban-764 ization in china: Based on input-output analysis. Chin $\mathrm{J}_{65}$ Popul Sci 5:57-66

766

Wang L, Wei Y, Huang Z (2016) Potential gains from car-767 bon emissions trading in china: A dea based estimation 768 on abatement cost savings. Omgea 63:48-59
Wang M, Huang Y (2015) China's environmental pollution and economic growth. China Econ Q 14:557-578

Wang Y, Xie Y, Zhou R, Hu X, Li X (2021) A comparative bibliometric analysis of chinese and foreign articles in environmental footprint family (eff) research. Environ Sci Pollut Res pp 1-14

Wang Z, Sun Y, Wang B (2019) How does the new-type urbanisation affect co2 emissions in china? an empirical analysis from the perspective of technological progress. Energy Econ 80:917-927

Xu QR, Wu ZY, Chen LT (2012) The vision, architecture and research models of smart city. J Ind Eng /Eng Manag 26:1-7

Xu S, Miao Y, Li Y, Zhou Y, Ma X, He Z, Zhao B, Wang S (2019a) What factors drive air pollutants in china? an analysis from the perspective of regional difference using a combined method of production decomposition analysis and logarithmic mean divisia index. Sustainability 11(17):1-19

Xu XC, Ren X, Chang ZH (2019b) Big data and green development. China Ind Econ 4:1-22

Yang HX, Zhang HX (2020) Global value chain embedding and technological innovation: Based on the production decomposition model. Stat Res 37:66-78

Yang ZH (2018) Can smart city improve economic efficiency: Quasi natural experiment based on smart city construction. Sci Technol Manage Res 10:263-266

Zhang K, Xu D, Li S (2019) The impact of environmental regulation on environmental pollution in china: An empirical study based on the synergistic effect of industrial agglomeration. Environ Sci Pollut Res 26(25):25775-25788

Zhang Y, Jin Y, Shen B (2020) Measuring the energy saving and co2 emissions reduction potential under china's belt and road initiative. Comput Econ 55:1095-1116 
Zhao D (2013) The research on the construction of the smart city in china. $\mathrm{PhD}$ thesis, Jilin University

Zhao X, Wu L, Li A (2017) Research on the efficiency of carbon trading market in china. Renewable and Sustainable Energy Reviews 79:1-8

Zhao X, Liu C, Sun C, Yang M (2020) Does stringent environmental regulation lead to a carbon haven effect? evidence from carbon-intensive industries in china. Energy Econ 86:1-10

Zheng S, Kahn ME (2017) A new era of pollution progress in urban china? J Econ Perspect 31(1):71-92 


\section{Supplementary Files}

This is a list of supplementary files associated with this preprint. Click to download.

- data611.dta 